\section{British tell too little too late}

BRITISH service chiefs flew in the face of safety warnings, and made servicemen "crawl, lie, walk and run" in radioactive dust from one of Britain's nuclear tests, the Australian Royal Commission was told in London last week.

Lord Penney, in charge of the test programme in Australia in the 1950s, told the commission that although he knew that the military had exposed men in such ways, he was not aware of documents warning the services of the dangers, in particular a document issued by the Admiralty in 1951 on gamma radiation which said that "all radiation dosage, however small, is harmful" and that men should be exposed to radiation only in the case of "demonstrable operational necessity'. Lord Penney added that it would have been for the services to decide how to study the effects of nuclear explosions.

One military requirement of the British tests, according to Penney, was for a ground-burst weapon. Mr Greg James, representing Australian veterans, told the inquiry last week that the object had been to cause a "dirty" explosion resulting in large amounts of radioactive fallout, accomplished at a test called "Marcoo" at Maralinga in 1956. James said that to the British military, the test was successful in that it showed that dirty explosions would have had the potential to kill large numbers of people.

Referring to still-secret British documents that remain classified, $\mathrm{Mr}$ Peter McClellan, the commission counsel, described last week a row between scientists and the Ministry of Defence about the need for the second bomb in the MOSAIC test series, G2. Lord Penney said that he had believed it necessary because the first in the series had not produced the required yield. Penney said that the British government had promised Australia that neither test would exceed two and a half times the HURRICANE test (25 kilotons), and that the second would be fired only if the first was unsuccessful.

$\mathrm{Mr} \mathrm{McClellan}$ said that the first test had indeed been a success but Penney was adamant that the second test had been necessary, despite the claim of officials who had described it as a waste of some $£ 3-£ 4$ million.

On testing underground, Lord Penney admitted to Mr Justice James McClelland, the commission's chairman, that his interest was stimulated only when a threat to atmospheric tests became apparent at the early test-ban talks in July 1958 . But he also admitted that the minor VIXEN trials which began in 1959 could have been successfully contained in deep pits, thereby reducing the spread of radioactive material.

Dispute about fallout from the TOTEM 1 test (October 1953) continued last week. Mr McClellan asserted that Penney had gone ahead with the test in atmospheric conditions so stable that the risk of fallout was increased, but Penney insisted that there had been no risk from the fallout of TOTEM 1.

The commission's search for British classified material also persists. Mr Robin Auld, the British government's counsel, said that his clients were now declassifying material and that they had produced more documents in the previous ten days than the Australian government had in six months. Mr Justice McClelland, however, tartly pointed out that it had been known for several months that the commission would be coming to Britain in early January, and that courtesy alone would have required "the mass of documents on the subject to have been collated, sifted and put into an easily accessible form". Susan Watts

\section{Detour for Galileo}

\section{Washington}

Gallieo, the US spacecraft due to begin its journey to Jupiter in May 1986, will make a detour around one of the larger asteroids, the National Aeronautics and Space Administration (NASA) has announced. The detour will add \$20-25 million to the cost of the mission which, NASA officials say, is a bargain price for what will be the first-ever close observation of a large asteroid.

A final decision will not be made until after launch; but if the detour is approved, Galileo will pass within $10,000 \mathrm{~km}$ of the asteroid, 29 Amphitrite. The plans involve mapping the surface with the spacecraft imaging equipment and probing the asteroid's mineral composition with spectrometers.

The Solar System Exploration Committee, a NASA advisory committee made up of space scientists, has for a long time been pressing for spacecraft exploration of asteroids as one part of an overall planetary exploration programme. From the Galileo fly-by, scientists hope to determine Amphitrite's mass, density, rotation rate, pole orientation and surface morphology. The data may also prove valuable in providing a basis for interpretation of ground-based observations of other asteroids.

Because of the extra expenditure of fue necessitated by the detour, Galileo's arrival at Jupiter will be delayed three months; present plans call for the spacecraft to enter orbit around the planet on 10 December 1988. The number of orbits around Jupiter will also have to be cut, from 11 to 10 .

NASA officials say the risks of bringing the spacecraft near the asteroid will be no greater than the risks that would be encountered in any event from passing through the asteroid belt on the way to Jupiter. Stephen Budiansky
European anti-trust law Ripping off red tape

Brussels

EUROPEAN companies (both indigenous and US or Japanese subsidiaries) jointly developing new products or processes will no longer need to spend time and risk untimely publicity by notifying the European Commission of each new joint venture. European Community anti-trust regulations obliging companies to notify the Commission of joint research and development agreements have been simplified. Fifteen years after the idea emerged, in the 1968 notice on cooperation between enterprises, there is now to be block-exemption from competition rules for agreements on joint research and development as well as the exploitation of results. Moreover, the regulation applies not only to research but also to joint marketing and production of the results of the research, an aspect championed by former research commissioner Etienne Davignon.

The new measure should be an important encouragement for European collaborative industrial research and development. There have even been some fears that the Commission's own Esprit programme on information technology would have fallen foul of the previous regulations. The blockexemption gives the official Community stamp to a practice common among the larger European companies undertaking research and development, and will in particular benefit small and medium-sized companies seeking joint research and production.

To avoid monopoly and to encourage diversity, however, the European Commission stipulates that the combined market share of production by cooperating companies should not exceed 20 per cent. But if companies do not sell products in competition with each other, there will be no restrictions on their collaboration in research programmes.

In addition, European companies marketing the fruits of joint research projects will also benefit by being freed from the requirement of active competition for the first five years, and for even longer while their joint market slice exceed does not 20 per cent.

In order to qualify for the block exemption from anti-trust regulations, European collaborations must be embodied in a written research programme. Companies must also agree not to pursue individual research and development in the areas of joint research, that access to results and patent rights should be available to all partners, that agreements with third parties on, for example, licensing should not be undertaken without the other partners' consent, and that each company should have exclusive distribution rights in its own country. 